\title{
GENERATING IDEAS AND MANAGING SUGGESTION SYSTEMS IN ORGANISATIONS: SOME EMPIRICAL EVIDENCE
}

\author{
AUTHORS: \\ Dr Andries J du Plessis \\ Unitec Business School \\ Unitec New Zealand \\ Private Bag 92025 \\ Auckland \\ New Zealand \\ Tel: +64 98154321 \\ E mail: aduplessis@unitec.ac.nz \\ Prof. Andrew E Marx \\ Department of Business Management \\ Faculty of Economics \& Management Sciences \\ University of Pretoria \\ Pretoria \\ Republic of South Africa \\ Tel: +27 124203392 \\ E-mail: andrew.marx@mweb.co.za \\ andrew.marx@up.ac.za \\ Mr Gregory Wilson \\ Unitec Business School \\ Unitec New Zealand \\ Private Bag 92025 \\ Auckland \\ New Zealand \\ Tel: +64 98154321 \\ E mail: gwilson@unitec.ac.nz
}




\title{
GENERATING IDEAS AND MANAGING SUGGESTION SYSTEMS IN ORGANISATIONS: SOME EMPIRICAL EVIDENCE
}

\begin{abstract}
Methods used to generate ideas and suggestions differ. It is generally accepted that employees from all levels in the organisation are involved in the design, but the respondents have different opinions. Suggestion systems consist of formal procedures; its success will depend on a number of factors. It should be explained during the induction process. This paper reports on research of suggestion systems executed through qualitative research with structured interviews in 21 organisations in New Zealand of which $90.48 \%$ are from the private sector and $9.52 \%$ are from the public sector. A 100\% response rate was achieved. To train all the people involved will help to be effective in the Idea Generation Programmes. Software should be used to administer and to manage the process effectively and efficiently. A flow chart was developed by the authors to assist with the generating of ideas system. Line managers should authorise implementation of suggestions. Due to financial issues, higher level approval is needed for rewards as well as for suggestions that could have implications on corporate level. It was found that managers will always play a pivotal role in the success of the suggestion system. Important issues are pointed out in the implications for managers section.
\end{abstract}

\section{INTRODUCTION}

In a global competitive business environment, where product lifecycles have shortened, businesses need managers and employees that are highly capable, multi-skilled and competent to maintain their competitive advantage. The global market and the global environment must be managed by knowledgeable managers and committed employees who will give their best to the organisation. Therefore a profound re-think of suggestion systems and what to do with the information gathered from employees is necessary to increase profits, retain the workforce and sustain their competitive advantage. In order to survive in the current competitive economies globally, organisations should use any possible management tool that contributes to their survival.

One of the most under-valued management tools available is the suggestion system; such a system consists of a formal procedure which encourages employees to think innovatively and creatively about their work and work environment, and to produce ideas which will benefit the organisation for which the employee will receive recognition, in one or another way, if the ideas are useful for the organisation. The success of the system will, however, depend on a number of factors, such as idea creation programmes, training 
or awareness programmes, correct administration of data received and the implementation of viable ideas or suggestions. Management must be committed and involved in all facets.

This article covers a literature review and reports on qualitative research with structured interviews. The creating and generating of ideas, different methods used, proper explanation of the programmes, and the ideal e-administration of the suggestion systems are discussed in the results and discussion section; the implications for managers and conclusion form the last part of the article.

\section{LITERATURE REVIEW}

According to Darragh-Jeromos (2005:18) a suggestion system should be integrated with the organisation culture. A common aim of a suggestion system is to achieve greater employee involvement which eventually leads to greater tangible benefits such as cost savings, and higher sales and intangible benefits like higher levels of morale (Crail, 2006:30-31).

Stone (2008:487) is of the opinion that employees have ideas regardless of whether or not the environment is conducive but the employee will not submit it if the environment is not seen as supportive. Therefore organisations must have incentives, which are proactive, in place for employees to feel that submission of their useable ideas will be rewarded. Incentives provide a very direct message to the employee and it is focused on their behaviour in achieving objectives; in our case idea generation programmes and participation in the suggestion system.

In contrast to Stone's view, Van Tonder (2006:201) is of the opinion that one of the most common observations during survey-driven diagnoses or research initiatives, is the cynicism and scepticism and often overt reluctance by employees to take part in surveys or the idea generation system. Usually the employee's response follows from substantial exposure to surveys or involvement to generating ideas in the workplace. One of the most 
pervasive perceptions likely to be encountered is that many of the past initiatives amounted to nothing. This perception normally arises from the absence of feedback on the outcomes or the non-implementation of ideas.

There are different ways to generate ideas (refer to Figure 1 below) but it is important that the method used must be clear, straight forward, and open to all potential participants (Wood, 2003:22). To be effective in the idea generation process it will help to train all the people involved. The ideal will be to create a culture and attitude of participation within the organisation. Creative behaviour conceptualises suggestions as creative acts while initiative adds one particular facet to the creative process idea. The notion of ownership which generally accrues from participation is a major consideration in the implementation of suggestions or ideas. It is through involving various stakeholder constituencies from the onset of the initiative, creating ideas, the pre-implementation stage, and during the diagnoses of generating ideas that psychological ownership for the suggestion programme is established (Van Tonder, 2006:217).

Within the framework of generating programmes to make employees aware of the benefits of a suggestion system, it is recognised that the human being possesses and often uses their power to derail, redirect or retard the initiative of the programme. Therefore more caution rather than less should be exercised to have the employees on board and totally committed to a suggestion programme. Methods to generate ideas should be clear, straight forward and open to all participants, teams and individuals. Figure 1 below is a flow chart to help organisations to make sure that all the methods are used and to involve all levels of employees in the process. Employees from all levels should be involved in designing the idea generation system.

An explanation and awareness of the suggestion system could be done during the induction stage of the organisation for new employees. Even for employees moving up to the next level by promotion should be exposed to this explanation. There are two broad categories of an induction programme where awareness and idea generation could be promoted: general topics of interest and specific, job-related issues to specific jobholders. 
Nel et al (2008) point out that policies, including suggestion programmes, should be the responsibility of the human resource department. They also state that policies and programmes must be developed in consultation with representatives from trade unions (if the organisation is unionised) and it must comply with relevant legislation. Dessler (2005:268) endorses this and adds that such information should be given at the second stage of the three conducting stages of induction.

The administration of the suggestion system seems to be a major hurdle to overcome. Holland, Sheehan, Donohue and Pyman (2007:60-65) are supporting what was explained above that information or data received must be evaluated and if useable must be implemented. Recordkeeping is of the utmost importance and the notion of e-admin has taken over. Ten years ago already Love (1998: 11) suggested that the system should start small and grow only if necessary. Administrative delays result in the employees getting the impression that the organisation does not view their ideas as worthwhile. An early acknowledgement of receipt of the suggestion is essential. Suggestion boxes, traditional ones and electronic ones (e-suggestion boxes), should be “cleared” on a daily basis. The suggestion system coordinator (e-admin coordinator) should make sure that employees who submit an idea receive a personal response to thank them (see Figure 1).

Available software should be used to manage the process effectively and efficiently. The software not only replaces the traditional suggestion box, but is able to acknowledge receipt, handle duplicated ideas, link ideas to evaluators and allow everyone to search for existing ideas and build on. Failure to acknowledge ideas is far more damaging than not seeking employees' views at all according to Sweetman (2005:45). Wood (2003:22) postulates that if supervisors are well trained to encourage ideas through the normal work teams or groups they are usually the gatekeepers of those ideas; this means that much of the initial administration of refusing and reviewing the ideas will be eliminated.

According to British Gas PLC (2006:43) the submission of suggestions online increased the number of suggestions because the process is more transparent and enables the 
employees to track their ideas from the point they made the suggestion, right through to evaluation and implementation.

The longer the time to give feedback and recognition, the fewer the suggestions submitted. The more immediate the feedback and recognition the more powerful it will be (refer to Figure 1 one below). In her study Nel (2008:11) found that two discouraging elements in the suggestion systems are the length of time taken to evaluate a suggestion and secondly the delay in recognition through sometimes poor communication channels.

There is a correlation between the number of suggestions submitted and the time taken to give feedback to the suggestor. Du Plessis and Paine (2007: 85) report that the power of feedback to employees is often underestimated. Employees' ideas and innovations are so important in any organisation because they are on the shop floor and are experiencing the advantages or disadvantages of what they are doing. The initial view should be the assumption that all suggestions are beneficial until the evaluation proves otherwise.

No matter how small the idea or suggestion, if it contributes to the organisation's profitability, survival, sustainability or maintaining its competitive advantage it should be recorded and implemented. The progress of submitted ideas should be monitored by the software in use and that includes implementation. The implementation of ideas should also be part of the supervisor's performance appraisal. Proper feedback should also be given to all stakeholders (see Figure 1 below).

\section{PROBLEM STATEMENT AND OBJECTIVE OF THIS ARTICLE}

It is expected that, due to the fact that most of the suggestion systems driven in New Zealand, are to a great extend of an informal nature, the evaluation of ideas and the implementation of good ones are neglected. This in turn could be contributed to the absence of proper idea generation programmes, a lack of awareness and publicity programmes and the acceptance of responsibility by all levels of management. 
The objective of this article is to report on empirical research undertaken by Unitec New Zealand, (New Zealand) on suggestion systems as applied in New Zealand organisations and the University of Pretoria, (South Africa). This article concentrates on idea generation programmes, awareness and publicity programmes, administration and processing, and corporate wide implications; other articles report on more research issues

\section{METHODOLOGY}

A number of critical success factors for suggestion systems were identified from the literature. From these critical factors the ten most important once were identified. A questionnaire was compiled by the University of Pretoria (UP) to establish to what extend these critical factors are complied with in organisations. The same questionnaire was used with permission from UP after minor modifications for an identical survey in New Zealand. Minor modifications involved updating and scrapping of some questions because the questionnaire was too long for use during short interviews in New Zealand.

The questionnaire was used and completed during personal interviews which were conducted in four main business areas, namely Auckland, Greater North, Manukau and Waitakere City. Table 1 below is a profile of the distribution of the respondents in the four business areas. A $100 \%$ response rate was achieved.

\section{Table 1: Profile of respondents by business area}

\begin{tabular}{|l|l|l|}
\hline Business Area & $\begin{array}{l}\text { Number of } \\
\text { organisations }\end{array}$ & $\begin{array}{l}\text { Percentage of } \\
\text { organisations }\end{array}$ \\
\hline Greater North & 6 & $28.57 \%$ \\
\hline Auckland & 10 & $47.62 \%$ \\
\hline Manukau & 4 & $19.05 \%$ \\
\hline Waitakere City & 1 & $4.76 \%$ \\
\hline Total & 21 & $100.00 \%$ \\
\hline
\end{tabular}

The number of employees employed by the organisations varies from a minimum of six employees to a maximum of 110, as reflected in table 2 below. 
Table 2: Profile of respondents by organisation size

\begin{tabular}{|l|l|l|}
\hline $\begin{array}{l}\text { Number of } \\
\text { employees }\end{array}$ & $\begin{array}{l}\text { Number of } \\
\text { organisations }\end{array}$ & $\begin{array}{l}\text { Percentage of } \\
\text { organisations }\end{array}$ \\
\hline $6-29$ & 8 & $38.10 \%$ \\
\hline $30-49$ & 8 & $38.10 \%$ \\
\hline $50-110$ & 5 & $23.80 \%$ \\
\hline Total & 21 & $100.00 \%$ \\
\hline
\end{tabular}

From the 21 organisations 19 (90.48\%) are from the private sector while two (9.52\%) are from the public sector. A total of $89.47 \%$ (17) of the private sector organisations are from industry.

\section{ANALYSIS OF THE RESULTS}

\section{Discussion}

It was found in the empirical study that only $19.05 \%$ of the organisations claimed to have a formal suggestion system. That means they have an official policy, certain structures and procedures in place. It is interesting to note that none of the organisations, whether formal or informal, have an exclusive name for their system. It could therefore be concluded that organisations will refer to "the suggestion system or suggestion scheme". Not one of the respondents believes that the name of the system will contribute to the success on the system.

Crail (2006:30) has a different view on this and refers to a name as "branding". It is essential to choose a name for the suggestion system that people, ideas and innovation could be associated with. It should be "smooth on the tongue", not too long and easy to handle in publicity. Almost three decades ago Alexander (1982:379) places a high priority on the correct name for a system. According to him it should be the first step in planning a suggestion system and idea generating programmes, because any further development and research could then be associated and identified with the name. Buchanan and Badham (2008:302) support this view but go one step further in saying 
that employees must have a conceptual understanding of the system and the name linked to it.

Figure 1: Flow Chart of the Idea Generation Process in Suggestion Systems

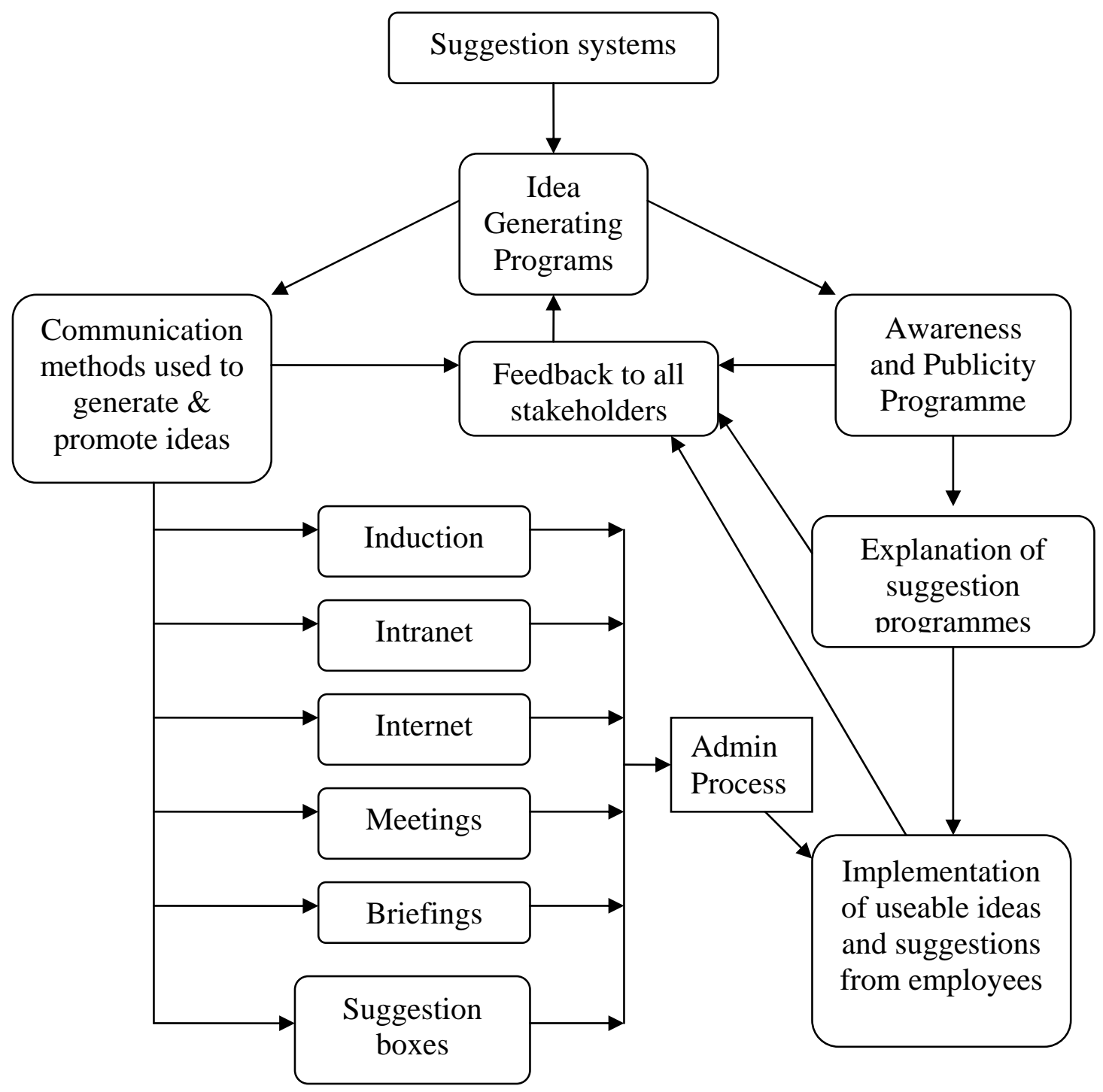

Source: Developed by the authors for this article

There was consensus among all the organisations that the evaluation of suggestions is completed in less than 90 days after it was submitted. This is an indication that the management is open for suggestions and that they value the ideas of employees. The 
fact, however, that $71.43 \%$ of the respondents either disagree or do not know whether suggestors are getting feedback on a regular basis during the evaluation period places a question mark on the commitment of management. The flow chart (Figure 1) above explains the flow of feedback.

\section{Methods used in Idea Generation Programmes}

The fact that $85.71 \%$ of the respondents agree that the methods that they use to generate ideas are clear and straight forward confirms that they have either a formal or informal suggestion system in place. The methods are also open to all potential participants including teams and individuals. With this high percentage one could easily deduce that it was going well in designing of the idea generation programmes as well if the methods used are so good; but it's a total different result in the next section.

\section{Employees involved in Idea Generation Programmes}

An alarming $38.10 \%$ of the respondents reported that their employees from all levels are not involved in the design of the idea generation system. A further $28.57 \%$ of the respondents were unsure; therefore two thirds (66.67\%) of their organisation's employees are excluded in the basic design of what could be a possible cost saving or a possible labour turnover decrease. Only a third (33.33\%) of the respondents is sure that their employees are involved and contribute positively to possible cost saving or attaining of their competitive advantage.

\section{Awareness and Publicity Programme}

Line managers are often the most important link in the idea generation programme. Employees and line managers are the people with the most knowledge of the job and it came as a surprise that $66.66 \%$ of the respondents admitted that no explanation of the suggestion programme forms part of the induction programme in their organisations. In Figure 1 above it is clear that the awareness and publicity programme follows the idea generating programme. The explanation could easily be done during the induction period. 


\section{Administration and Processing}

The question was put forward to the respondents whether software is used to submit and process suggestions. Only $4.76 \%$ of the respondents agreed that software is in use for administration and processing. Almost all (95.24\%) of the respondents responded that they don't use any software for the said issues. It can be deduced that the organisations are too small to layout huge amounts of money on systems that they think could be managed manually.

\section{Gathering of ideas}

More than three quarters (80.95\%) of the respondents agreed and strongly agreed that they receive their ideas via email, intranet, internet or face to face. It can be deduced that the old fashioned way of meetings face to face still has its value. In Figure 1 above all the aforementioned methods are mentioned as a method to gather ideas.

\section{Specific section suggestions}

A disappointing $19.05 \%$ of the respondents agreed that suggestions received in a specific section are authorised by the line manager and implemented immediately. It can be deduced that line managers either don't want to take responsibility or they don't have the authority or are not empowered to do it. If the line manager does not take the responsibility, who must? Surely, the suggestor cannot implement the suggestion without the approval of the line manager? If there is agreement on this, then it should be the responsibility of the line manager. A total of $71.43 \%$ of the respondents were unsure what happens in their organisation. It is almost three quarters of the organisations in the main business areas in Auckland and the surrounding business areas that are not sure whose responsibility it is or who must record and implement suggestions. Recognition and rewards also fall under this heading with $80.95 \%$ of the respondents not knowing or disagreeing that line managers are responsible for it. 


\section{Higher level of authority to agree}

With the previous section and responses to that question in mind, it is not surprising that the response to this question was almost a 100\% (95.24\%) that a higher level of authority needs to approve rewarding or implementation of suggestions. Only 4.76\% were unsure. It can be said therefore that higher approval is necessary due to capital investment. It is also deduced that the supervisor only makes a recommendation about the acceptability of the idea in the concerned work area or section and then enter it in the process for higher level sign off.

\section{Corporate level implications}

With reference to the implementation of ideas and suggestions consensus (95.24\%) was reached that it is the responsibility of the highest level in the organisation to approve recognition and rewards and the implication of any suggestions. If the line managers cannot take responsibility for rewards and the implementation of the suggestions it is understandable that not in one of the participating organisations implementation of suggestions form part of the line managers’ performance appraisal.

\section{IMPLICATIONS FOR MANAGEMENT}

Although it might not be a written clause in their employment agreement, employees do want to be recognised or awarded for their efforts and achievements in the organisation under the psychological contract. Higher level authority in the organisation must ensure that they do not neglect recognising, rewarding and implementation of useable ideas and suggestions.

Management's involvement in the effort to make the suggestion system a success creates a cascade effect down to baseline employees, which will encourage them to become active in the system.

Therefore, the line managers must support the Idea Generation Programmes; without them supporting the programmes, it is hardly likely that subordinates will come up with new ideas. If there is an air of negativity, it will pervade down to the subordinates with 
the result that participation dwindles. The line manager's role is an important aspect in the success of the scheme.

Most of the resistance and resentment results from lack of knowledge. It is therefore important that line managers are trained in how they and their subordinates can benefit from the suggestion system, how to evaluate ideas, how to administratively assist subordinates and how to encourage ideas, which means they must know how to develop ideas from their group or team. Line managers will always remain pivotal in the success of the suggestion system.

Management is engaged in evaluating the suggestions therefore they are instrumental in determining the advantages of the idea. Managers should maintain a good relationship with their subordinates, develop the Idea Generation Programmes and motivate them to submit their suggestions. Feedback to suggestors should be documented and managers should also become active in the system to make it a success.

\section{CONCLUSION}

To survive in the current competitive economies globally, organisations should use any possible management tool that contributes to their survival. The most under-valued management tool available is the suggestion system which consists of a formal procedure that encourages employees to think innovatively and creatively about their work and work environment, and to produce ideas. To achieve greater employee involvement that eventually leads to greater tangible benefits such as cost savings, better sales and intangible benefits like higher levels of morale are some of the goals.

Organisations must have incentives in place for employees to feel that submission of their useable ideas will be rewarded. Explanation and awareness of the suggestion system could be done during the induction stage, even for employees getting promotion. Administrative delays result in the employees getting the impression that the organisation does not view their ideas as worthwhile but it can be minimised with the use of software to manage the process effectively and efficiently. 
Feedback should also be given to all stakeholders as is explained in Figure 1. A flow chart (Figure 1) was developed to assist organisations in the Idea Generating Process. Some interesting responses were discussed and the implications for management were pointed out.

The motivational effect that recognition and rewarding have, must never be under estimated. Therefore, to be successful with a suggestion system, management must get actively involved by creating the opportunities for employees to submit their ideas, get those ideas properly evaluated, give recognition when it is due and implement them as soon as possible.

\section{REFERENCES}

Alexander, W. 1982. Suggestions are alive and well at US Steel. Annual Industrial Conference Proceedings, pp. 337 - 383.

American Productivity Centre. 1982. Techniques to spruce up suggestion box. The Productivity letter, Vol.1, No. 6.

Anonymous. 2004. Interesting stuff. Human Resources, April, 2004 London, p. 8. [Online] Available from: $\underline{\text { http://0- }}$ proquest.umi.com.innopac.up.ac.za:80/pqdweb?did=620704991\&sid=6\&Fmt

Buchanan, D. A. and Badham, R. J. 2008. Power, Politics and Organisational Change. Sage Publications, London.

Centaur Communications, Ltd . 2006. Suggestion schemes: Flaming good ideas. Employee Benefits, February 10, 2006, London, p. 43. [Online] Available from: http://0proquest.umi.com.innopac.up.ac.za:80/pqdweb?did=985812451\&sid=6\&Fmt

Crail, M. 2006. Fresh ideas from the floor. Personnel Today, June 20, 2006, p. 30.

Darragh-Jeromos, P. 2005. A suggestion system that works for you. Super Vision, Vol. 66, Issue 7, p. 18.

Dessler, G. 2005. Human resources management. 7th ed Upper Saddle River, NJ: Prentice-Hall

Du Plessis, A.J. (2007). Change, Organisational Development and Culture: Human Resource's role in a future S A. International Review of Business Research Papers. 3(1), March: 1-10.

Du Plessis, A. J., Paine, S. (2007). Managing of Human Resources and Employment Relations in New Zealand's Retail Industry. The International Journal of Knowledge, Culture and Change Management. 7(2): 83-91 
Du Plessis, A. J. (2007). Strategies, external relations, ethics and integrity: Human resource manager's role in a future South Africa. Commercium Journal, 7 (1): $51-63$.

Frese, M., Teng, E. \& Wijnen, C.J.D. 1999. Helping to improve suggestion systems: Predictors of making suggestions in companies. Journal of Organizational Behaviour, Vol. 20, Issue 97, p.1139. [Online] Available from: http://0proquest.umi.com.innopac.up.ac.za:80/pqdweb?did=48248835\&sid=6\&Fmt

Holland, P., Sheehan, C., Donohue, R. and Pyman, A. 2007. Contemporary issues and challenges in HRM. Tilde University Press, Australia.

Love, T. 1998.Managing your small business. Nation’s Business, Vol. 86, Issue 5, p. 11.

National Association of Suggestion Systems (NASS). 1983. Management: Participation ... Support ... Involvement. NASSPAK. Second Quarter, Chicago, pp. 1-6.

Nel, L 2008. The usefulness of corporate ethics programmes in integrating ethics into an organisation's culture. Unpublished Master of International Communication Thesis, Unitec New Zealand.

Nel, P.S., Werner, A., Haasbroek, G.D., Poisat, P., Sono, T., Schultz, H.B., (2008). Human Resources Management. $7^{\text {th }}$ edition. Cape Town: Oxford University Press

Prather, C.W. \& Turrell, M.C. 2002. Involve everyone in the innovation process. Research Technology Management, Vol. 45, Issue 5, p. 13.

Reuter, V.G. 1976. A new look at Suggestion Systems. Journal of Suggestion Management, Vol.27, pp. 6 - 15.

Seinwerth, HW. 1948. Getting Results from Suggestion Plans. First Ed., New York: Mc Grow-Hill Book Co., Inc., 223p.

Stern, S. 2006. Interesting Stuff. Human Resources, March 2006, London, p.7. [Online] Available from: http://0proquest.umi.com.innopac.up.ac.za:80/pqdweb?did=1009986941\&sid=5\&Fm

Stone, R. J. 2008. Human resource management. $6^{\text {th }}$ edition. John Wiley and Sons, Australia Ltd

Sweetman, P. 2005. How to ... seek suggestions from staff. People Management, Vol. 11, Issue 13, Personnel Publications Ltd., pp. 44 - 45.

Van Tonder, C. L. 2006. Organisational change. Van Schaik publishers, South Africa.

Van Tonder, C. L. 2006. Organisational change. Van Schaik Publishers, Pretoria.

Wood, A. 2003. Managing employees' ideas: From where do ideas come? The Journal for Quality and Participation, Vol. 26, Issue 2, p. 22. 